\title{
Community-University Partnerships: Achieving continuity in the face of change
}

\author{
LINDA SILKA, ROBERT FORRANT, BRENDA BOND, PATRICIA COFFEY, \\ ROBIN TOOF, DAN TOOMEY, DAVID TURCOTTE AND CHERYL WEST
}

\begin{abstract}
challenge most community-university partnerships will face Aafter having established themselves is how to maintain continuity in the face of change. The problems besetting communities continually shift as new issues bubble up. Similarly, the goals of the university partners often fluctuate. And the partners themselves shift: people working in non-government organizations often move in and out of positions and university partners may change with tenure or shifts in university priorities. In light of all of this flux, can stable community-university partnerships be built and, if so, how?

This problem is not an insignificant one (Maurrassee 2001). Now that universities are once again expressing interest in working with the communities that surround them, community leaders who have had past experiences with universities are responding to such overtures with caution and even skepticism (Holland 2005; Lerner \& Simon 1998; Nyden 2005). Communities perhaps rightly question the
\end{abstract}

Gateways: International Journal of Community Research and Engagement No 1 (2008): 128-149

(๖) UTSePress and the authors 
staying power of this latest university enthusiasm (Edwards \& Marullo 1999; Silka 1999). Continuity in university involvement requires some shared vision but this is often in short supply in academic environments (Kennedy 1997; Rhodes 1998; Silka 2001). University faculty are notoriously difficult to lead, with faculty operating largely as independent entrepreneurs pursuing their own interests (Bowen \& Shapiro 1998). In light of these challenges, how can continuity be built into community-university partnerships?

These are issues we have struggled with over the past decade at the University of Massachusetts Lowell (UML) (Forrant \& Silka 2006; Forrant \& Silka 1999). UML is a comprehensive public university located in the northeast of the United States. The region in which UML is situated has undergone rapid transformation (MassInc 2006; Silka 2004). Lowell is now home to the second largest Cambodian population in the United States, all countries in Africa are represented among Lowell's residents, and many Central and South Americans (for example, some 15000 Brazilians) live in the Lowell area (Lotspeich, Fix, Perez-Lopez, \& Ost 2003). The majority of the youth now in the Lowell school system are from minority backgrounds. At the same time, this region is undergoing economic restructuring (Forrant 2001a; Gittell \& Flynn 1995; Moscovitch 1990): northeastern Massachusetts was once a major locus for manufacturing but many of these high-paying industrial jobs have gone overseas, leaving behind unemployment and environmental contamination. Because Massachusetts is a high cost region in which to do business, there is a constant need for the development of new opportunities to replace the industries that have moved elsewhere. Against this background, the issues that call for immediate response are never entirely predictable. Issues sometimes emerge abruptly and with urgency: a gang death may occur, leading to renewed concern over what is happening to youth; or housing costs may show dramatic spikes, leading to increased attention on the gap in affordability.

This search for continuity in partnerships is made all the more challenging by the changes reshaping UML as its 'baby boomer' faculty nears retirement (Clark 2004; Hutchings, Huber, \& Golde 2006). Like many universities, UML is currently undergoing its greatest faculty turnover since the university's inception. Over onequarter of the faculty have retired in the last few years, and these 
retirees have been replaced by approximately one hundred new faculty, bringing in new interests, goals and areas of scholarship. In some departments, the majority of the faculty has been at UML for a mere year or two. In addition, the university administrative leadership has changed, with most having served in their leadership roles for just a few short years. With these administrative changes have come attempts to promote new emphases on outreach and research intended to align university efforts more visibly with regional needs on areas such as the environment, green chemistry, nanotechnology, the work environment, and regional economic development (Forrant 2001b). How then can stability in communityuniversity collaborations be maintained in the face of these changes, both in the problems to be tackled and in the partners participating in collaborations?

At UML much experimentation has gone into trying to answer this question. This article describes an approach that has been developed over a series of summer projects occurring over the past decade. A number of different approaches have been employed, from harnessing the inherent strengths of communities (the 'multipliereffect') to linking one-shot content funding with other already existing organizations and projects. This article looks at four broad areas of consideration: the selection criteria for projects; the effective and creative use of content funding; the need for clear communication of a university's capacities and strengths; and the need to get new faculty on board. At essence, however, is the need to build shared responses if continuity is to be an integral, embedded part of the process. Moreover, approaches, if they are to be truly inclusive, must reach out to entire universities and a broad range of partners (Lynton \& Elman 1987; O'Meara \& Rice 2005; Todd, Ebata, \& Hughes 1998). Yet despite the importance of continuity, it cannot be made the centerpiece of partnership efforts: in most partnerships, resources are simply too scarce and time too limited to devote to selffocused 'process goals' such as sustainability. Instead, if seamlessness is to be achieved, it must emerge as a side benefit of the activities that are already a natural focus of partnerships. The question that partnerships find themselves confronted with, then, is how to go about their ever-shifting topic-focused work so as to produce continuity as a predictable byproduct. 


\section{THE LOWELl APPROACH}

For the last eight years, our UML partnership has used content funding that is available every summer as a means of responding to shifting priorities. Each year a summer research-action project is developed to target an issue that has emerged into prominence, often with unexpected urgency. UML provides a university-wide committee, the Committee on Industrial Theory and Assessment (CITA), with resources of approximately $\$ 20000$ per annum to carry out this research-action project in which graduate students and high school students look for innovative ways to investigate an issue of joint interest to the community and university. These topics have been highly varied and have included:

- New Immigrant Businesses (1998): Many in the community were pointing out that at a time of loss of major industries in the Merrimack Valley, many new small immigrant businesses were emerging. Little was known about these businesses: their focus, their owners, their customers, their links to the community and their needs for technical assistance from UML and the Small Business Assistance Center. Much has been written about the ways in which immigrant businesses may be more tightly connected to their customer base and may contribute to higher 'multiplier effects' in their communities.

- Youth Transportation/Youth Asset Mapping (1999): Many of Lowell's youth do not have access to private transport. Public transport is their only means for getting to jobs, recreation and entertainment. Schools, youth-serving organizations and many others were struggling to understand youth experience with public transportation and the nature of their unmet needs. The demographic character of Lowell's youth is changing rapidly. Few in the city are familiar with the resources available for youth and youth-serving organizations. Can Lowell's youth use geographic information systems and other community mapping resources to identify assets?

- Women-owned Businesses (2000): Women-owned businesses were emerging in Lowell. Again, little was known about these businesses: their owners, their customers, their links to the 
community, their needs for technical assistance and partnership with organizations such as UML's Center for Women and Work.

- The Housing Crisis (2001): Lowell was rapidly becoming a magnet for those priced out of the greater Boston housing market. Many different entities in the city were trying to understand what was going on with the housing market and what could be done. Each group seemed to think that some other group had the tools or resources to address the problem.

- Understanding and Addressing Budget Cutbacks Within Lowell's Youth Service Agencies (2002/2003): A 'perfect storm' of cutbacks began in earnest in 2002. Federal, state and local funding for programs dramatically dropped, as did foundation funding. Each individual organization was aware of its own crisis. However, little had been done to gather together information about the magnitude of these cutbacks so that their implications could be considered as a whole.

- Community Connections/UML Signature Outreach Areas (2004): UML had reached the point where community groups were beginning to sense that the university had much to offer. But partners were reporting that they were struggling to make sense of the rich variety of resources and who within UML might act as a resource.

- Spreading the Word on Sustainability (2005): UML's CITA hosted a conference on Sustainability: Inside and Outside Universities, published an edited volume in this area, and surveyed UML students about their views on this aspect of the university's mission. Who within UML was doing work in this area? What are the views of sustainability among prospective students, community partners and others?

- 'What's Art Got to Do With It?': Economic Development and the Arts (2006): The city of Lowell's Master Plan as well as many of the initiatives of the city's Division of Planning and Development emphasize the arts as a source of economic revitalization. An Arts Overlay district has been created and much of the city's promotion emphasizes the 'creative economy'. This approach to economic revitalization has its advocates and its critics, but little has been known about how those immersed in or experiencing this latest Lowell Renaissance view the events and opportunities/needs for partnership. 


\section{THE SELECTION CRITERIA FOR TOPICS}

The brief outlines given above of our summer research projects provide a glimpse into Lowell's shifting priorities. Across these diverse initiatives, the larger question we have pursued over the past decade is whether individual projects can simultaneously contribute to an understanding of particular issues and be a means of achieving continuity within partnerships. As mentioned already, much experimentation has gone into testing different approaches within our summer projects to find a strategy that works. We have now arrived at an approach that we find helps us to achieve goals in very different content areas while at the same time strengthening our capacity for continuity. Put briefly, when choosing a project we look for a topic with the following characteristics:

- the collection of local data is needed, and this data can be gathered within the time span of a summer

- the input of both the community and the university is necessary for success

- the language and terms lend themselves to community definitions rather than concepts framed solely by university departments or disciplines

- progress in solving the problems cannot be achieved merely by review of the literature but instead requires the integration of scholarly research with the knowledge of the community

- no single discipline can be said to own the topic

- the university has some competencies in the area but also needs to strengthen capacities

- students from diverse disciplines can readily contribute through their involvement

- the approach or topic is generative and can spawn work in many different directions

- the topic lends itself to action.

When topics are selected with these characteristics in mind, we have found they serve as great opportunities for partnership building that integrates the independent strengths of the community and the university. 
Some might mistakenly view the summer projects as mere pilot work - and it is indeed the case that more extensive studies do often follow. But it is important to note the respects in which this work differs from preliminary pilots. The goal of the summer projects is to collect information that is ready to be used for local decision-making and is not merely intended to lay the groundwork for additional indepth study or large scale experiments elsewhere. The local community is not a laboratory for testing out new practices that will then be applied in the real world; the local community is the real world.

Moreover, the focus is not on data collection per se; often it is on the framing of issues, the result of which may or may not point to the need for data collection. Concurrent with this, we have revised the role we see for traditional academic deliverables such as journal articles and conference presentations. The primary aim of the summer projects is not publications; instead the dual aims are, first, to make the usefulness of information central to how data are collected and, secondly, to make reliance on data a comfortable, routine part of all local decision making. Toward these ends, we do not rely on journal articles and conference presentations as primary vehicles; we use policy reports, videos, websites and community forums as well as extensive use of local media, including cable television, local radio, and print media. And in all of this we take into account the audiences and objectives and we reach out to policy makers so that the findings will get used.

Despite their obvious diversity, the summer projects listed above share important features. Each had an urgency to it, a timeliness. The information was needed quickly, often because some immediate policy change was under consideration. In most cases the long delay involved in securing external funding for data collection was not viable. Each topic also had the advantage of drawing on multiple domains. That is to say, the topics were inherently interdisciplinary and because they did not 'belong' to any single field, they encouraged disciplines to pool their efforts to achieve greater understanding. These areas were also chosen because of their high visibility. Their salience meant not only that people were often willing to devote scarce resources to the issues, but also that media attention could easily be gained to highlight the combined efforts of students, partners, and the city. And the topics themselves were 
generative: they had the potential to contribute in many different and often unexpected ways to teaching, research and outreach.

To better illustrate some of the above ideas, this article will discuss in more detail two examples from the summer research projects. The first example, new immigrant business (1998), amply demonstrates how tapping into the latent knowledge and strengths of a community can lead to many and varied opportunities for future partnerships. The second example, economic development and the arts (2006), looks at how issues of ownership can be sidestepped through creative partnership.

\section{UTILIZING THE 'MULTIPLIER EFFECT'}

Some changes emerge rapidly and go to the very heart of community life (Migration Policy Institute 2004). Such was the case with immigrant businesses beginning to emerge in Lowell at the beginning of this decade. As noted earlier, Lowell over the previous decade had undergone dramatic demographic shifts. The number of Asian families had increased rapidly, and the size and prominence of other immigrant groups was rapidly increasing as well. One of the most visible signs of these changes was the large number of small immigrant businesses - restaurants, retail stores, insurance agencies, beauty parlors, auto body shops, and the like — that were suddenly emerging throughout the city's many neighborhoods (Turcotte \& Silka 2007). These new businesses were all the more important in light of the changing economy and the region's loss of major manufacturers. Small immigrant businesses were seen as perhaps becoming the core of the region's new economy. So, what were these businesses? In what ways were they contributing to the local economy? What kinds of assistance did they need from the university, from the city and from other organizations?

These questions were on the minds of many at the time that the 1998 Summer Project was undertaken. The approach used in this first summer project pursued continuity by implicitly drawing an analogy with the concept of the 'multiplier effect.' That is, the choice was made to focus on information that had high potential to be used, reused and re-circulated throughout the community, where each use would have the potential to establish new links between groups that were previously unconnected. 
At the outset of the project, no inventory existed of the new businesses, of their number of employees, of the nature of their customer base or of the kinds of practices and acumen they brought to their new businesses. Yet a growing body of literature on immigrant businesses pointed to the possibility that these businesses might be important anchors in their communities: immigrant businesses generally had higher 'multiplier effects' than other businesses, which is to say that the dollars they generated tended to recycle through the community more times than dollars generated by nonimmigrant businesses (Jennings, in press; Turcotte \& Silka 2007; Wilson \& Martin 1982). And the literature suggested that these businesses might differ from nonimmigrant businesses in other respects as well: there were discussions of import substitution; of how these businesses seemed to be helping their compatriots learn about the new society; and in general, of how these small businesses acted as key institutions within their neighborhoods.

Given this context, during the summer of 1998 we brought together a team of graduate students and high school youth who represented different immigrant groups now living in Lowell. To learn about these businesses would not be simple. No central registry existed and some of the businesses were owned by new residents who were undocumented or had yet to achieve compliance with American tax laws and environmental regulations. Many of the business owners spoke a primary language other than English and had little time to devote to answering esoteric questions about their businesses. Under the direction of faculty well versed in economic development, and with the support of some members of the community-university advisory board who were themselves immigrant business owners, the team developed an interview protocol, a neighborhood sampling strategy and a method for 'mining' fragmentary data from existing sources. Throughout the summer, students were thrust into situations that showed them the importance of, yet difficulties with, real-life data collection. Students saw first-hand the challenges that arise in attempting to gather information from small business owners. Barbershop owners, for example, continued to cut hair even while being interviewed because they could not stop or leave their barbershop to attend a focus group. Despite these difficulties, the team was able to create a detailed report 
about these new businesses, the niches they were filling and the needs they foresaw for assistance and support. ${ }^{1}$

The potential for spinoffs that would create continuity was considerable. Once information about the businesses was gathered, then UML and other organizations could begin to assess a number of factors, including the ways that they might need to change their assistance practices in order to meet the needs of these businesses; how new cooperative organizations such as Asian chambers of commerce could be developed if the felt need was there; how business and regional economic and social development faculty could better enable their students to collaborate with these immigrant businesses; and how to support the anchoring effects of these businesses on neighborhoods, such as in creating opportunities and reducing crime.

And, indeed, the outgrowths of this summer project were numerous. The report that was created (about the new businesses, how they went about their work, the kinds of contributions they were making to the local economy and the needs they had for assistance if they were to further develop their businesses) was widely circulated and read. This report was placed online so that it would be available across time to different groups and organizations. Various community forums were held at which the information became the focus of discussion and planning. The findings contributed to planning for cooperative ventures such as the Asian American Business Association and a partnership bringing together immigrant restaurants with organizations focused on increasing the recycling and use of food wastes.

\section{SIDESTEPPING 'OWNERSHIP' ISSUES}

The arts and economic development summer project, briefly described next, illustrates a different strategy for pursuing continuity. Partnerships not infrequently bump up against ownership issues. As noted earlier, one of our goals was to select summer project topics that were not owned by particular disciplines. This is easier said than done and it can often stand in the way of attempts to achieve continuity. In community-university partnerships, individuals put boundary markers around a topic, either in words or actions,

${ }^{1}$ The report is available at

http: / / www.uml.edu/ centers/CFWC / Reports / Microsoft $\% 20$ Word\%20Docum1.doc 
demarcating it as belonging to their discipline, their department or their community-based organization. Although positive energy can result when a group sees a problem as their responsibility, too often territoriality and ossification are the consequence and the same unproductive ways of attacking the problem are repeated. How then can the positive aspects of felt ownership be capitalized upon and the problematic aspects avoided?

How can the examination of the issue be moved beyond the constraints of a single disciplinary perspective? Disciplinary ownership claims can be sidestepped by redrawing the outlines of a topic. Prospects for continuity then increase as more people see their perspectives as relevant. A broader partnership can then be bolstered even as the focus stays on new program creation for a specific topic.

Within the context of the summer projects at UML, we have seen this ownership dilemma resurface every year. Consider the arts emphasis of the 2006 summer project. In recent years Lowell has focused on the arts as an economic development strategy (Florida, 2002). Such a strategy could readily be seen as corresponding to the expertise arena of particular university departments or certain branches of city government, yet what is taking place in Lowell deals with much more, including issues of class, race, established traditions and the needs of long-term residents versus newcomers.

Yet partnership examples in this particular summer project illustrated how ownership claims could be transcended. One local organization, in particular, demonstrated great resourcefulness in showing the potential of bringing diverse partners together to define the arts. This organization, the Revolving Museum focuses on promoting public art but sees this goal as achievable only by linking it to other goals (that is, building community understanding of public art, revitalizing the city, and strengthening youth leadership). ${ }^{2}$ The Revolving Museum (RM) has been inventive in seeking out partners whose interests on the surface bear little relationship to the arts: those in computer science, green chemistry, or math, for example. The RM sought out UML's Program in Green Chemistry as a way for students to see how art, chemistry, and progressive environmental practices can be integrated in a community. And the RM participated in a partnership with K-16 groups to design after school programs bringing together math and the arts, again to widen understanding of

\footnotetext{
${ }^{2}$ The Revolving Museum at http:/ / www.revolvingmuseum.org
} 
the art while at the same time improving student math skills. Although these particular examples focus on schools, the RM has engaged in the same process with projects designed to encourage non-school partners to work together in devising new ways to revitalize abandoned spaces through the use of arts.

\section{EFFECTIVE AND CREATIVE Use OF CONTENT Funding}

Resources for university-community partnerships are often limited. One resource that partnerships often do have at hand is funding dedicated to the pursuit of a particular topic or content area. This important resource often has not been examined for its potential to enhance continuity. Content funding that is aimed at diverse and specific topics is often seen as sowing the seeds of discontinuity, but we argue here that it can instead be creatively harnessed to build continuity within partnerships. In the summer project of 2001, continuity was pursued by focusing on a topic but at the same time finding opportunities to link it to related interests and thus draw in new partners.

For some time Lowell, the Merrimack Valley and Massachusetts have been in the midst of a crisis in housing affordability (Santiago, Jennings, \& Carrion 2005; University of Massachusetts Donahue Institute 1997). The statistics are daunting. Housing costs in Massachusetts rank among the highest in the US and the increases in housing costs are rapidly outstripping wages (MassInc 2006; Stone 2000). Young people are leaving this region in greater numbers than anywhere else in the US because of the region's high cost of living. And the region's ability to attract new businesses is increasingly being undermined by escalating housing costs.

In the summer of 2001, an investigation of the housing crisis had already begun at the UML Center for Family, Work, and Community. However, because this investigation was grant-funded, the fear was that this focus would disappear once the external funding was exhausted. With the CITA summer project, a research team of graduate students and high school students aimed their efforts at enlarging and extending the impact of this one-shot grant-funded initiative. Many steps were taken to embed this grant work within ongoing streams of partnership activity. The summer team helped to publicize the project and link it to various university departments and community partners. Information was shared with those who 
previously had not seen their work as housing-related, such as those studying health who might find intriguing the national trends linking housing to health issues. Graduate classes were drawn in, with students as a part of their coursework providing training to community leaders in assessing the implications for housing under Lowell's twenty-year Master Plan. And past initiatives were mined for their possible links to housing. For example, immigrants groups in Lowell had previously participated in a grant-funded initiative entitled 'Celebrating diverse traditions of community preservation' in which, over a series of months, they shared information about best practices in their home countries on housing and other economic development topics. The team gathered examples of how other community-university partnerships had contributed to solving housing crises and helped to create a final report organized around the community's questions regarding the housing crisis. ${ }^{3}$

\section{CLEAR COMMUNICATION OF A UNIVERSITY'S CAPACITIES AND STRENGTHS}

Effective partnerships arise out of a clear understanding of each other's strengths, capabilities and interests. UML's community partners have repeatedly expressed their frustrations with the 'black box' character of the university. Community partners reported continually needing to ask such questions as: What are the resources of the university? What are its areas of strengths? Who does what? It was frequently unclear to potential partners what the university could offer in the way of partnership.

Often in describing resources of a community or university, the approach takes the form of mere cataloguing. A list is made of the available resources and the resulting compendium is then widely distributed. The problem with such an approach, however, is that it tends to be inert. It lacks an action component and has limited potential to generate activity. We wondered whether information might be gathered and presented in ways that contribute to continuity by implicitly signaling importance, interdisciplinarity, links to pre-existing community interests and needs, to pre-existing faculty strengths and to the university's mission. And could all of this be done in a way that makes these underlying criteria integral

\footnotetext{
${ }^{3}$ The full report is available at http: / / www.uml.edu/ centers / CFWC/ Reports / Housing\%2520Report.pdf.
} 
without being salient?

In the summer of 2004 the CITA graduate student-high school student team undertook this task. They gathered information about eight UML signature outreach areas by looking at what has been done, who has been involved and what opportunities for collaborations are suggested by these signature outreach areas. ${ }^{4}$ Although the community was ostensibly the audience for the information, in fact the entire university was the target. We wanted to link the university with the needs that had been identified by the community.

The goal was to expose university faculty, staff and students to opportunities for collaboration by providing them with examples of the innovative work already being done by their colleagues. The information could then help to support continuity. This information about the signature outreach areas is increasingly being widely used. The information was introduced into the deliberations of the UML Community Outreach Task Force, it was used by the UML's Community-University Advisory Board and it appears in the UML Community Clearinghouse that is used by community partners to identify resources and opportunities within UML.

\section{GETTING NEW FACULTY ON BOARD}

Finally, if continuity in partnership is to be the hallmark of a community-university partnership, new faculty must be drawn into the kinds of collaborations described throughout this article. Yet involving new faculty is difficult because new PhDs, in our experience, are especially anxious about getting their own research underway and, unfortunately, such research often does not lend itself to the multidisciplinary thrust of community-university partnerships. The research of new faculty is typically narrow in scope, reflecting as it does the subdisciplinary focus typically called for in a dissertation. How do we address this issue of involving new faculty and could we do so in ways that do not place their scholarly advancement at risk?

Our partnership's way out of this dilemma has been to continually try to shape our projects in ways that signal to new faculty how the projects link to their research programs but at the

\footnotetext{
${ }^{4}$ Information on the outreach areas is available at http:/ / www.clearinghouse.uml.edu/outreach_areas.htm
} 
same time indicate how the project might enable them to expand their research in a direction of interest to them. Our investigation of youth program cutbacks, for example, took into account cutbacks in those areas that would be of particular interest to new faculty with strengths in particular areas. We suggested how these cutbacks might be better understood if an economic analysis were to occur for example, or if the impact on youth-serving agencies were to be investigated, or if innovative uses of tools such as geographic information analyses were brought into the investigations. We have also worked to identify and disseminate to new faculty and to departmental tenure committees information about publication outlets that welcome the kinds of interdisciplinary research done through partnerships. And, we have offered workshops for new faculty on partnership grant writing, which illustrate the pathway to publication that is possible through grant-funded partnership research. We are finding that such approaches are beginning to achieve success.

\section{A Final Thought: PARTNerships in Times of Program CUTBACKS}

Opportunities to create programs, as the above illustrates, can stimulate the formation of new and even unanticipated partnerships. In times of program cutbacks, partnerships often become all the more important yet the prospects for maintenance and continuity are often vastly reduced during these times.

In 2002/ 2003 the summer project examined the nature and extent of the funding cutbacks that were occurring at all levels of government. Our goal was to see if, as a partnership, we could find new ways to capture the nature of the losses so that these cutbacks could be viewed with fresh eyes. The goal was not merely to document the losses but to find effective ways to frame these losses. The data gathering and reporting were organized to take into account the kind of substitution analysis that permeated discussions, whereby people assumed that the impact of losses from one kind of funding could be minimized by substituting other sources of funding. The community report produced at the summer's end documented cutbacks but then framed the cutbacks by directly confronting the problems with this substitution analysis. The report showed the ways in which, if funding cutbacks from different sources all came at the 
same time, the substitution approach would not address the shortfalls. The lack of a safety net was concretely illustrated.

The findings were presented at several community forums where the discussion was oriented on stemming this crisis. The partnership mounted a media campaign to publicize the results. In the interim, while waiting for the funding situation to improve, we began to focus on avenues for innovation. In other words, might there be innovative ways to carry out programs and meet youth needs in the face of severe budget cutbacks? One UML graduate course took up this task directly, combing the literature for best practice examples of innovative approaches to youth programming in times of budget cutbacks. This information was then used to create community tip sheets and hold community workshops demonstrating how such strategies could be implemented in Lowell.

The highlighting of program cutbacks turned out to be useful as far as it went. But only now, nearly half a decade later, has our partnership begun to realize that we missed opportunities to use program loss as a wake-up call to raise questions about whether community indicators are being kept that will allow for the tracking of changes. At the time, we did not do an analysis of existing indicators nor did we consider which indicators might be needed if impacts such as loss of youth services were to be better monitored in the future. Youth violence is now erupting in the city, yet we are not positioned to say whether the upsurge in youth violence in any way parallels the cutbacks in after school programming in particular neighborhoods. As a partnership, we have begun to recognize that attention to continuity ought to be used to raise questions in a variety of areas including data collection and use.

\section{CONCLUSION}

As noted at the outset, all of the common ways that communities and universities come together pose problems for continuity. Grant funded forays into the community often lurch from one project to the next. Courses begin and end. Individual faculty research projects are faculty driven and often limited in scope and duration. External funding takes so long to acquire that often the urgency has passed before the funding is in place. Continuity can be imposed through the creation of a university central office for community partnerships but too often such an approach can become too bureaucratic or is viewed 
with wariness by faculty fearful of excessive administrative control. The result is that the opportunities for timeliness and continuity are limited. In this article, we have argued for a different approach to continuity, one in which the resources that are available for content projects are used by community-university partnerships to respond in a timely fashion to shifting problems in ways that build shared responses and thereby continuity.

Some might assert that the approach argued for here - building continuity through structures while varying the topic focus - will not be successful in the face of changing administrative support or shifting patterns of priorities in community partners. Clearly such changes pose obstacles to continuity, and the consequences of these changes can never be fully anticipated or warded against. What we have found over a decade of experience, however, is that the approach described here has a sufficient degree of both flexibility and specificity to provide opportunities for growth and adaptation in the face of such changes. And we are seeing first-hand the value of this approach in the face of change. Once again, many of our community partners are undergoing significant changes in their staffing and funding while at the same time the upper administration at our university has been transformed. Our chancellor is new as are many of the vice chancellors. Yet, in the face of these changes, we have been able to garner support for partnerships by showing how these past practices have built a body of knowledge and experience that has served our region well. The work continues to be supported and valued.

While specific actions that have the effect of building continuity have been the focus of this article, we are finding ourselves increasingly cognizant of the importance of how we use language. It has been our experience that the active use of metaphors sometimes provides the best way for people to see the importance of creating continuity in community-university partnerships. In our partnership discussions we sometimes bring up the image of a relay race to raise questions about the need to plan for transferring the baton (that is, we need to plan for how we are going to have one class or group of summer research participants smoothly hand over their findings to others). Or, to capture the importance of moving quickly and sometimes without much preparation time, we might liken ourselves to a strike force or s.w.a.t. team that must go into action on a suddenly pressing issue without every fact or analysis we might 
need. The use of the apt metaphor or analogy within our community conversations has become an important part of how we go about learning together.

Universities have much in the way of intellectual capital, but questions remain as to how these resources can most effectively be brought to bear on community problems. In this time of experimentation, the answer to what will work best is not yet clear. As universities around the globe test out different possibilities across a variety of settings, a literature on best practices will begin to emerge to guide future efforts. Here we have suggested a number of possible approaches worthy of further investigation.

\section{REFERENCES}

Bowen, WG \& Shapiro, HT (eds) 1998, Universities and their leadership, Princeton University Press, Princeton, NJ.

Clark, RL 2004, 'Changing faculty demographics and the need for new policies,' TIAA-CREF Institute, available at http:/ / www.tiaa-

crefinstitute.org/research/papers/040104a.html, viewed 1 September 2007.

Edwards, B \& Marullo, S (eds) 1999, 'Universities in troubled times Institutional responses,' American Behavioral Scientist, vol. 42, no. 5, full issue.

Florida, R 2002, The rise of the creative class: And how it's transforming work, leisure, community and everyday life, Basic Books, New York.

Forrant, R 2001a, 'Random acts of assistance or purposeful intervention: The University of Massachusetts Lowell and the regional development process,' in R Forrant, J Pyle, W Lazonick, \& C Levenstein (eds), Approaches to sustainable development, University of Massachusetts Press, Amherst, Massachusetts.

Forrant, R 2001b, 'Pulling together in Lowell: The university and the regional development process,' European Planning Studies, vol. 9, no. 5, pp. 613-628.

Forrant, R, Pyle, J, Lazonick, W, \& Levenstein, C (eds) 2001, Approaches to sustainable development, University of Massachusetts Press, Amherst, Massachusetts. 
Forrant, R \& Silka, L 2006, 'Introduction: Inside and out - what's it all about?' in R Forrant and L Silka (eds), Inside and out: Universities and education for sustainable development, Baywood, New York.

Forrant, R \& Silka, L 1999, 'Thinking and doing — doing and thinking: The University of Massachusetts Lowell and the community development process,' American Behavioral Scientist, vol. 42, pp. 814-826.

Gittell, RJ \& Flynn, PM 1995, 'Lowell, the high tech success story: What went wrong?', New England Economic Review, March/April.

Hall, T \& Silka, L 2007, 'Housing for everyone,' in E Hamin, L Silka, \& P Geigis (eds), Citizens as planners, University of Massachusetts Press, Amherst, Massachusetts.

Holland, B 2005, 'New view of research for the twenty-first century: The role of engaged scholarship,' in L Silka (ed), Scholarship in action: Applied research and community change, US Housing and Urban Development, Washington, DC.

Hutchings, P, Huber, MT, \& Golde, CM 2006, 'Integrating work and life: A vision for a changing academy', Perspectives: Carnegie Foundation for the advancement of teaching, available at http:/ / www.carnegiefoundation.org/perspectives/index.asp, viewed 1 September 2007.

Jennings, J 2007, 'Social capital, race, and the future of inner city neighborhoods,' in J Jennings \& A Withorn (eds), Politics, neighborhoods, and the misuse of social capital, Palgrave-Macmillan, New York.

Kennedy, D 1997, Academic duty, Harvard University Press, Cambridge, MA.

Lerner, RM \& Simon, LAK 1998, 'The new American outreach university,' in RM Lerner \& LAK Simon (eds), University-Community collaborations for the twenty-first century, Garland, New York.

Lotspeich, K, Fix, M, Perez-Lopez, D, \& Ost, J 2003, A profile of the foreignborn in Lowell, Massachusetts, The Urban Institute, Washington, DC.

Lynton, EA \& Elman, SE 1987, New priorities for the university: Meeting society's needs for applied knowledge and competent individuals, Jossey-Bass, San Francisco. 
MassInc. 2006, 'CommonWealth agenda 2006', CommonWealth: Politics, ideas, civic life in Massachusetts, available at http:/ / www.massinc.org, viewed 1 September 2007.

Maurrasse, DJ 2001, Beyond the campus: How colleges and universities form partnerships with their communities, Routledge, New York.

Moscovitch, E 1990, 'The downturn in the New England economy: What lies behind it?' New England Economic Review, July / August.

Migration Policy Institute, 2004, Building the new American community: Newcomer immigration and inclusion experiences in non-traditional gateway cities, Report for the Nation Conference of State Legislatures.

Nyden, P 2005, 'The challenges and opportunities of engaged research' in L Silka (ed.), Scholarship in action: Applied research and community change, US Housing and Urban Development, Washington DC.

O'Meara, KA \& Rice, RE 2005, Faculty priorities reconsidered: Rewarding multiple forms of scholarship, Jossey-Bass, San Francisco.

Pyle, J \& Forrant, R (eds) 2004, Universities and regional economic development, Edgar Elgar Press, London.

Rhodes, FHT 1998, 'The university and its critics,' in WG Bowen \& HT Shapiro (eds), Universities and their leadership, Princeton University Press, Princeton, New Jersey.

Silka, L 1999, 'Paradoxes of partnership: Reflections on universitycommunity partnerships,' in N Kleniewski \& G Rabrenovic (eds), Research in politics and society: Community politics and policies, JAI Press Inc, Stamford, Connecticut.

Silka, L 2001, 'Addressing the challenges of community collaborations: Centers as opportunities for interdisciplinary innovations,' in R Forrant, J Pyle, W Lazonick, \& C Levenstein (eds), Approaches to sustainable development, University of Massachusetts Press, Amherst, Massachusetts.

Silka, L 2004, 'A university enters into its regional economy: Models for integrated action,' in J Pyle \& R Forrant (eds), Universities and Regional Economic Development, Edgar Elgar Press, London. 
Santiago, J, Jennings, J, \& Carrion, L 2005, 'Immigrant homebuyers in Lawrence and Lowell, Massachusetts: Keys to the revitalization of cities,' available at http:/ / www.ilctr.org/news/pdf/Immigrant_Homebuyers.pdf, viewed 1 September 2007.

Stone, M 2000. Situation critical report 2000: Meeting the Needs of Lower-Income Massachusetts Residents, available at

http:/ / www.mccormack.umb.edu/research/download/MccormackInstitut eReport2000.pdf, viewed 1 September 2007.

Todd, CM, Ebata, AT, \& Hughes, R 1998, 'Making university and community collaborations work,' in RM Lerner \& LAK Simon (eds), University-Community collaborations for the twenty-first century, Garland, New York.

Turcotte, D \& Silka, L 2007, 'Reflections on the concept of social capital: Complex partnerships in southeast Asian refugee and immigrant communities,' in J Jennings (ed.), Race, neighborhoods, and the misuse of social capital, Palgrave-Macmillan, New York.

University of Massachusetts Donahue Institute, 1997, A profile of housing in Massachusetts, available at http:/ / www.donahue.umassp.edu/docs/ profhous-97, viewed 1 September 2007.

Wilson, K \& Martin, A 1982, 'Ethnic enclaves, a comparison of the Cuban and black economies in Miami,' American Journal of Sociology, vol. 88, pp. 135-160.

\section{ACKNOWLEDGEMENTS}

Funding for the work described here was provided by University of Massachusetts Lowell's Committee on Industrial Theory and Assessment. Graduate students who participated in these projects as staff included Theresa Bader, Shawn Barry, Ioana Crisan, Susan Dempsey, Heather Derby, Jagruti Desai, Cathy Ferreira, Gustavo Garcia-Barragan, Jennifer Gaudet, Toni-Marie Henry, Marc Horne, Brandy Jablonski, Joseph Meager, Palak Mehta, Theresa Milewski, Taner Osman, George Papakostas, John Penney, Deepa Rao, John Reynolds, Jennifer Santos, Manjula Sastry, Brian Twomey, Henri Urey, Magdalena Vedawati, Vicki Watson and Henrique Wilson. Undergraduate students included Leidy Arias, Nerissa Gleason, Sokny Luong, and Nate Osit. High school students included Ronnie Campbell, Chan Chea, Timothy Dalton, Tram Dang, Linda Det, Linda Doung, Juliana Estrada, Alex Iraheta, Jenneh Kaikai, Ratani Khan, Jeffrey Khorn, Venus Luong Andrew Morel, Joel Morel, Sammie Meth, Shelagh Murphy, Mary Neor, Sokley Oeur, Sandy Phomsopha, Ellen Proeung, Milton Robles, 
Senvey Sam, Chhavy Sinuon, Sreyroth Tom, Phally Ty, Jhony Valencia,

Maribel Vilchis and Narin Yem. Faculty members Meg Bond and Jean Pyle helped to lead the Summer 2000 Project on Women-Owned Businesses. 